\title{
The Health Record and the Digital Patient
}

The growth of technology and the need for the systematization of information has transformed the most traditional form of paper-based health records into various types of electronic applications. Such apps were developed with the goal of improving the quality of health systems. Among them, the Electronic Health Record (EHR) is notable for allowing structured data organization, providing support for the decision making of medical teams. Numerous EHRs have been developed to meet the demands of clinics and hospitals. They aim to provide a unidirectional perspective to assist with bureaucratic issues and care needs, from healthcare provider to patient.

With the advent of the internet and cloud computing, electronic health records have become important tools, not just allowing doctors to record and organize information about their patients, but notably functioning as the primary vehicle through which doctors and patients can quickly, easily and safely access and input health data.

In the world of Digital Health, patients have apps which are integrated with electronic medical records which make it possible, for example, to send laboratory and imaging exam results. Numerous medical devices such as watches, bracelets and sensors capable of continuously sending qualified data and warning signals about blood pressure, oximetry, body temperature and heart rate are currently available. Through phone applications and adapters, blood glucose values and electrocardiographic tracings or even dermatological and otological images are sent to medical centers with just a few taps on a cell phone screen.

Cloud-based electronic health records have become platforms for data communication, digitization, storage and interpretation.

In countries where regulatory issues are more advanced, EHRs have become integrated with teleconsultations, tele-interconsultations and tele-diagnosis platforms. In the USA, in 2018, a single service provider performed more than 3 million tele-consultations, all properly integrated with EHRs, following information security protocols. Regardless of the current debates on issues surrounding telemedicine, EHRs will be the main tools in the Digital Health universe.

In this long trajectory from simple paper records to complex platforms, electronic medical records have had to adapt to the needs of patients. They have become friendlier and easier to use. For health professionals, EHRs have become empowering tools for patients to engage in their own treatment. Despite this evolution, there remain obstacles to the implementation of EHRs. A lack of standardized terminology results in the 
loss or impracticality of many of the resources that might otherwise be available, such as alerts, decision support systems, clinical research and others. The lack of security and confidentiality resources in itself creates suspicion, adding to a lack of trust among users. The recent General Personal Data Protection Act (or LGPDP), which establishes rules in Brazil for the handling of personal information by individuals or legal entities, has brought more legal certainty for everyone involved, including patients, healthcare professionals, healthcare operators and system developers.

Health professionals need to be trained and develop skills to incorporate technology into their practice. Technology does not ask for "permission" to enter. It becomes accepted through the support of digital users, in this case, the Digital Patient.

\section{Renata Aranha}

Professora Associada da Faculdade de Medicina da Universidade do Estado do Rio de Janeiro (UERJ), Mestre e Doutora em Epidemiologia pelo IMS-UERJ, Cofundadora da Atol

\section{Bruno Horstmann (1D)}

Médico pela Universidade Federal Fluminense (UFF), Especialista em Medicina do Trabalho pela Universidade Federal Fluminense (UFF).

\section{REFERENCES}

1. Dias D, Cunha JPS. Wearable health devices: vital sign monitoring, systems and Technologies. Sensors. 2018;18(8):1-28.

2. HealthWatch Technologies [Internet]. Kfar Saba: HealthWatch Technologies Ltda; 2016 [acesso em 10 maio 2019]. Disponível em: http://www.personal-healthwatch.com

3. Brocheto AD, Dos Reis ZC, Ganzer PP. Prontuário Eletrônico do Paciente (PEP): análise em Hospital da Serra Gaúcha (RS). Rev Eletr Gest Saúde. 2015;(N. Extra 3):2053-74.

4. Massad EE, Marin HF, Azevedo RS. O prontuário eletrônico do paciente na assistência, informação e conhecimento médico. São Paulo: UNIFESP; 2003. 


\section{ERRATUM}

In the editorial " The Health Record and the Digital Patient”, published in the Revista Brasileira de Geriatria e Gerontologia v. 22, n. 3, p. 1-2, 2019, DOI: http://dx.doi.org/10.1590/1981-22562019022.180151, the DOI number on p. 1 is incorrect, and the e-location on pages 1 and 2 are incorrect.

Instead of: http://dx.doi.org/10.1590/1981-22562019022.180151

The reference should read: https://doi.org/10.1590/1981-22562019022.190151

Instead of: e180151

The reference should read: e190151 